February 13, 2017

\title{
Extremely Thermophilic Energy Metabolisms: Biotechnological Prospects
}

\author{
Christopher T. Straub ${ }^{1}$, Benjamin M. Zeldes ${ }^{1}$, Gerrit J. Schut ${ }^{2}$, \\ Michael W.W. Adams ${ }^{2}$, and Robert M. Kelly ${ }^{1 *}$
}


Abstract: New strategies for metabolic engineering of extremely thermophilic microorganisms to produce bio-based fuels and chemicals could leverage pathways and physiological features resident in extreme thermophiles for improved outcomes. Furthermore, very recent advances in genetic tools for these microorganisms make it possible for them to serve as metabolic engineering hosts. Beyond providing a higher temperature alternative to mesophilic platforms, exploitation of strategic metabolic characteristics of high temperature microorganisms grants new opportunities for biotechnological products. This review considers recent developments in extreme thermophile biology as they relate to new horizons for energy biotechnology.

\section{Introduction}

By the dawn of the $21^{\text {st }}$ century, the metabolic basis for microbial life could be probed through the strategic application of modern (molecular genetics, functional genomics) and classical (laboratory pure culture) methods. Such endeavors were largely focused on what are now referred to as 'model organisms'. Escherichia coli (gram-negative), Bacillus subtilis (grampositive) and Saccharomyces cerevisiae (eukaryote), among other mesophilic microorganisms, were examined with increasingly sophisticated experimental and computational tools to the point that prospects for synthetic life forms and minimal genomes could be considered [1]. While studies of model microorganisms laid the foundation for understanding the complex machinery and mechanisms of life, they only hinted at the diversity and unique niches within which life exists and develops. Now, as the circle of 'model' microorganisms expands with molecular genetic tools becoming more widespread [2], so too does the potential of microbial biotechnology. Extremophiles epitomize this vast potential, particularly those prospering at the upper thermal limits for life. The lens of modern biology facilitates a more discerning look at these microorganisms for new metabolic pathways and physiological features that can be exploited for technological benefits, especially as this relates to reducing the reliance upon fossil 
fuels to meet the energy demands of modern society. In this review, we consider recent developments in the biology and biotechnology of extreme thermophiles, microorganisms that grow optimally $\left(\mathrm{T}_{\mathrm{opt}}\right)$ at and above $70^{\circ} \mathrm{C}$, as these relate to bioenergy.

\section{Genetics}

To capture the full potential of extremely thermophilic microorganisms for technologically relevant applications, molecular genetic tools are needed. These are important not only for understanding the intrinsic basis of their metabolism and physiology, but to establish them as metabolic engineering platforms [3]. To this end, over the past decade, genetic systems for several extreme thermophiles have been developed and utilized in multiple laboratories, including Sulfolobus sp. $\left(\mathrm{T}_{\mathrm{opt}}=\sim 80^{\circ} \mathrm{C}\right)$ [4-6], Thermococcus kodakarensis $\left(\mathrm{T}_{\mathrm{opt}}=85^{\circ} \mathrm{C}\right)$ [7], Pyrococcus furiosus $\left(\mathrm{T}_{\mathrm{opt}}=100^{\circ} \mathrm{C}\right) \quad[8,9]$, Thermus thermophilus $\left(\mathrm{T}_{\mathrm{opt}}=72^{\circ} \mathrm{C}\right) \quad[10]$, Thermoanaerobacter mathranii $\left(\mathrm{T}_{\mathrm{opt}}=75^{\circ} \mathrm{C}\right)[11]$ and Caldicellulosiruptor bescii $\left(\mathrm{T}_{\mathrm{opt}}=78^{\circ} \mathrm{C}\right)$ [12]. The COM1 strain of the hyperthermophilic archaeon Pyrococcus furiosus, which was isolated in the laboratory, exhibits natural competence with chromosomal insertion achieved for gene clusters as large as $17 \mathrm{~kb}$ [13]. Recently, a high temperature kanamycin resistance-based selection system (originally developed in Thermus thermophilus [14]) was adapted for use in the

extremely thermophilic bacterium Caldicellulosiruptor bescii, significantly improving genetic manipulations with this bacterium and opening the door for metabolic engineering efforts [15]. Genetic tools for the extremely thermoacidophilic archaeon Metallosphaera sedula $\left(\mathrm{T}_{\mathrm{opt}}=75^{\circ} \mathrm{C}\right)$ [16] and the hyperthermophilic bacterium Thermotoga sp. $\left(T_{\text {opt }}=\sim 80^{\circ} \mathrm{C}\right)[17,18]$ have also been reported but are in their early stages and not yet widely utilized. As genetic tools for extreme thermophiles become more versatile and reliable, new methods for genome editing (CRISPR) and promoter design can be incorporated into metabolic engineering efforts, thereby accelerating development of these microorganisms for industrial biotechnology. 


\section{Impact of Environmental Factors on Host Metabolism}

Microbial metabolic activity can be significantly influenced by environmental factors, creating a strategic opportunity for metabolic engineering. Extreme thermophiles could function as hosts for more moderately thermophilic enzymes and pathways, with the host metabolism operating in the 'background' while the heterologous pathways proceed. P. furiosus typically produces $\mathrm{CO}_{2}$, acetate, and hydrogen from hexoses. Yet, insertion of a lactate dehydrogenase from C. bescii, an organism with optimal growth temperatures some $20^{\circ} \mathrm{C}$ below that of $P$. furiosus, enabled temperature-dependent gene regulation by insertion of the Idh gene downstream of the cold shock promoter. Lactate was not detected near the optimal temperature for $P$. furiosus $\left(98^{\circ} \mathrm{C}\right)$, yet lactate $(0.3 \mathrm{~g} / \mathrm{L})$ was produced near the optimal temperature of the heterologous enzyme $\left(72^{\circ} \mathrm{C}\right)[19]$. Efforts with P. furiosus to produce 3-hydroxypropionate (3HP), temperatures nearly $30^{\circ} \mathrm{C}$ below its optimal growth temperature were used in the production phase to minimize the background metabolism of the host [20]. In another study, metabolic profiling of $P$. furiosus revealed acetoin production $(0.6 \mathrm{~g} / \mathrm{L})$ during growth at sub-optimal temperatures $\left(70-80^{\circ} \mathrm{C}\right)$, yet this compound was absent at its optimal growth temperature of $100^{\circ} \mathrm{C}$. [21]. These results with $P$. furiosus illustrate the potential for temperature-based gene regulation, a metabolic engineering strategy closely aligned with extreme thermophily.

In addition to thermal gene regulation demonstrated in $P$. furiosus, other environmental changes can impact core metabolism, as was demonstrated through growth substrate changes in the metabolically versatile Sulfolobus solfataricus [22]. Toward that end, a genome-based metabolic network was constructed for S. solfataricus [23], which was expanded and validated by comparing metabolite, transcript, and enzyme activity levels during growth on glucose and fucose [24]. Significant differences were noted between archaeal and bacterial core metabolism. A reversal of the ribulose-monophosphate pathway (involved in formaldehyde uptake in methanotrophs) was already known as an alternative to the pentose phosphate pathway in $S$. 
solfataricus, and in many other archaea [25]. This latest effort suggests that S. solfataricus uses a portion of the $3 \mathrm{HP} / 4 \mathrm{HB}$ cycle in a manner similar to the glyoxylate shunt. $S$. solfataricus is able to obtain less biomass from growth on fucose than on glucose. To make up for this, it appears cells growing on fucose up-regulate enzymes of the 3HP/4HB cycle (resulting in a concomitant increase in chemical intermediates) in an attempt to replenish TCA cycle intermediates while minimizing loss of carbon during growth on this less nutritive sugar. These differences between archaea and bacteria will be important to understand, as archaea are considered further as metabolic engineering hosts.

\section{Lignocellullose \& Biomass Degradation}

Efforts to transform native biomass, such as grasses and trees, into fuels and chemicals are hindered by the complex nature of lignocellulose and the plant cell wall structure. Most efforts to transform these feedstocks into commercial products rely upon chemical and thermal pretreatment, followed by addition of exogenous enzyme cocktails to produce fermentable hexoses and pentoses. As a further complication, many fermentative organisms, such as the moderate thermophile Clostridium thermocellum, utilize only hexose sugars [26].

Several species in the genus Caldicellulosiruptor not only degrade lignocellulosic biomass as a sole carbon source and access its carbohydrate content but also co-ferment hexoses and pentoses from complex polysaccharides [26]. Unique to the genus are a suite of glycoside hydrolases, polysaccharide lyases, and carbohydrate esterases, many of which are modular, multi-domain enzymes [27]. A number of these enzymes have been characterized in detail to determine substrate specificity, kinetics, and importance to the overall complex process of accessing the carbohydrate content of lignocellulosic feedstocks [28]. One such multi-domain enzyme has been demonstrated as the most potent cellulolytic enzyme identified to date, with seven times higher activity compared to the standard exo- and endo- cellullase mixture [29]. These features provided the basis a system in which biomass is directly converted to products 
of interest without the expense of significant pre-treatment and exogenous enzyme additions that adversely impact the economics of lignocellulosic feedstock processes.

Marine-based substrates for bio-based fuels and chemicals, such as algae and related seaweeds, are much less recalcitrant due to their lack of lignin and crystalline cellulose. The moderately thermophilic marine bacterium Defluviitalea phaphyphila $\left(T_{\mathrm{opt}} 60^{\circ} \mathrm{C}\right)$ produced ethanol $(10 \mathrm{~g} / \mathrm{L})$ at yields approaching $50 \%$ of theoretical from brown algae [30,31]. The ability to metabolize alginate, laminarin, and mannitol from the algae demonstrates that marine-based photosynthetic carbon sources could be renewable feedstocks, potentially avoiding land use conflicts.

\section{Carbon Dioxide Fixation}

Two of the six presently known $\mathrm{CO}_{2}$ fixation pathways are found exclusively in extremely thermoacidophilic archaea. Metallosphaera sedula utilizes the 3-hydroxypropionate/4hydroxybutyrate $(3 \mathrm{HP} / 4 \mathrm{HB})$ cycle [32], while Ignicoccus hospitalis $\left(\mathrm{T}_{\mathrm{opt}}=90^{\circ} \mathrm{C}\right)$ contains the closely related dicarboxylate/4-hydroxybutyrate cycle [33]. These cycles, related to both the reverse TCA cycle found in many thermophiles and the 3-hydroxypropionate cycle first identified in the thermophilic green non-sulfur bacterium Chloroflexus aurantiacus $\left(\mathrm{T}_{\mathrm{opt}}=55^{\circ} \mathrm{C}\right)$, provide opportunities for products as pathway intermediates (see Figure 1) as well as the potential to incorporate $\mathrm{CO}_{2}$. To this end, a reaction kinetic model was recently reported for the $3 \mathrm{HB} / 4 \mathrm{HB}$ cycle as it appears in the Sulfolobales which was employed to evaluate metabolic engineering options for using all or parts of the cycle to produce bio-based chemicals [34].

Fixation of $\mathrm{CO}_{2}$ (either from the atmosphere or from industrial emissions) to create renewable chemicals is a global, aspirational goal to address and reduce greenhouse gas emissions. Plants and algae as renewable feedstocks rely upon the Calvin-Benson-Bassham (CBB) carbon fixation cycle. However, other fixation pathways present opportunities to incorporate $\mathrm{CO}_{2}$ directly into fuels and chemicals, either bypassing carbohydrates as 
intermediates or supplementing the carbohydrates for improved mass yield. Incorporation and reduction of $\mathrm{CO}_{2}$ requires significant energy input, which is often provided through chemolithoautotrophic growth in certain extreme thermophiles. Utilizing a $\mathrm{CO}_{2}$ incorporation step in a metabolically engineered pathway can be most advantageous for products containing highly-oxidized, functional groups (e.g., succinic acid) that maintain carbon in a highly oxidized state. This approach minimizes energy and redox inputs that would otherwise be required to incorporate carbon in a more reduced state. Along these lines, recombinant $P$. furiosus strains have been created that express five genes encoding three enzymes from the $M$. sedula 3HP/4HB cycle to produce 3-hydroxypropionate from $\mathrm{CO}_{2}$ and maltose $[35,36]$. While the incorporation of $\mathrm{CO}_{2}$ occurs at the expense of ATP and is followed by two NADPH-dependent steps, traditional Embden-Meyerhof-Parnas glycolysis generates two ATP and four reducing equivalents from glucose, thus creating an energy and redox neutral pathway if reductases are present to transfer electrons to NADPH. ,

\section{Iron and Sulfur Oxidation for Chemolithoautotrophy}

Most metabolic engineering efforts are centered upon the fermentation of saccharides, such that energy and reducing equivalents are obtained through central metabolism and pyruvate is converted to a desired metabolite. However, there exist other options for cellular bioenergetics. Thermoacidophiles inhabit environments that are often devoid of organic carbon and oxidize metals and sulfur to provide the reducing potential and energy for autotrophy. By oxidizing Fe(II) to $\mathrm{Fe}(\mathrm{III})$, organisms such as Metallosphaera sedula, can generate energy and reducing equivalents required to grow autotrophically. As the thermodynamics of carbon fixation require many $\mathrm{Fe}(\mathrm{II})$ atoms in order to fix a single carbon, relying solely upon $\mathrm{Fe}(\mathrm{II})$ oxidation presents a challenge to conceiving a viable biotechnological process with reduced metal as the energy source. 
Metal species can also act as important electron sinks in certain environments where electron acceptors, such as oxygen and sulfur, are absent. The thermoacidophilic archaeon, Ferroglobus placidus $\left(\mathrm{T}_{\mathrm{opt}} 85^{\circ} \mathrm{C}\right)$, has been shown to utilize benzene as the electron donor with its oxidation coupled to the reduction of $\mathrm{Fe}(\mathrm{III})$ to $\mathrm{Fe}(\mathrm{II})$ [37]. While the pathways of aromatic degradation were not completely elucidated, evidence was provided to confirm benzene consumption and reduction of $\mathrm{Fe}(\mathrm{III})$ as the sole means of energy metabolism. By combining both iron oxidation and reduction in a cycle (Figure 2), the potential exists to utilize complex aromatic substances, such as lignin, as a substrate for production of chemicals [38].

In addition to iron oxidation, many extreme thermoacidophiles grow by the oxidation of metal sulfides (i.e., pyrite and chalcopyrite) [39,40] and elemental sulfur [41]. Growth on metallic ores is strategic for acidophiles, as the low $\mathrm{pH}$ solubilizes the metal substrate. On the other hand, elemental sulfur is sparingly soluble, and low $\mathrm{pH}$ prevents abiotic formation of more soluble sulfur compounds, such as thiosulfate and polysulfides [42]. An acidophilic solution to sulfur oxidation, first identified in thermoacidophilic archaea [43], is cytoplasmic sulfur oxygenase reductase (SOR), which has also been reported recently in acidophilic bacteria [44]. In archaea, SOR seems to be essential for growth on elemental sulfur, although species that lack SOR may be able to grow on other sulfur compounds.

\section{Carbon Monoxide as Source of Reducing Power}

The utilization of $\mathrm{CO}$ (typically from a syngas stream) by microorganisms has been considered for some time as a route to bio-based products. While certain anaerobic microorganisms can utilize CO via the Wood-Ljungdahl pathway (reductive acetyl-CoA), the ability to engineer in cofactors necessary for this pathway adds complexity to the metabolic engineering effort. However, other options exist to utilize CO. P. furiosus has recently been engineered with a 16gene cluster encoding CO dehydrogenase/hydrogenase from Thermococcus onnurineus, 
allowing the generation of an ion-gradient via the oxidation of $\mathrm{CO}$ to $\mathrm{CO}_{2}$ coupled to the evolution of $\mathrm{H}_{2}$ [45].

$P$. furiosus can conserve energy from the ion gradient via an ATP synthase, thus permitting the oxidation of $\mathrm{CO}$ to act as the primary energy source. This pathway does not fix carbon and thus a complex carbon source (maltose or peptides) is necessary to provide for biosynthesis. Since $P$. furiosus typically produces acetate as a metabolic by-product from these complex carbon sources, the demonstration of acetate consumption during growth on $\mathrm{CO}$ indicates the reverse reaction with regeneration of acetyl-CoA. In another interesting study, a two-step process with $T$. onnurineus and Thermoanaerobacter kivui $\left(\mathrm{T}_{\mathrm{opt}} 65^{\circ} \mathrm{C}\right)$ converted a CObased gas mixture, typical of steel mill waste streams, to acetate. In the first step, T. onnurineus converted $70 \%$ of the $\mathrm{CO}$ to $\mathrm{CO}_{2}$ and $\mathrm{H}_{2}$, which was then fed to Thermoanaerobacter kivui ( $\mathrm{T}_{\text {opt }}$ $\left.65^{\circ} \mathrm{C}\right)$, obtaining acetate $(\sim 0.5 \mathrm{~g} / \mathrm{L})$ [46]. The two-stage process, utilizing a carboxytrophic thermophilic archaeon and an autoacetogenic thermophilic bacterium, beneficially exploits their native capabilities toward transferring waste syngas-like streams into chemicals. Further genetic engineering efforts may permit more interesting products to be generated in such processes.

\section{Hydrogen/Hydrogenases/Bifurcation}

Many microorganisms, including extreme thermophiles, generate hydrogen gas to recycle reducing equivalents generated during oxidative metabolism. The thermodynamics of this reaction at higher temperatures can be advantageous. A temperature change from mesophilic conditions $\left(37^{\circ} \mathrm{C}\right)$ to hyperthermophilic environments $\left(100^{\circ} \mathrm{C}\right)$ increases the entropy term of the Gibbs free energy equation $(\Delta G=\Delta H-T \cdot \Delta S)$ by $20 \%$. Given that the majority of biological reactions operate close to equilibrium, this can transform a reaction that may be endergonic at mesophilic conditions to one that is exergonic and favorable at thermophilic conditions. Such is the case with many hydrogenases, since $\mathrm{H}_{2}$ production from reducing equivalents becomes

much more favorable at elevated temperatures [47]. An excellent example is the case of 
formate oxidation to hydrogen by the archaeon Thermococcus onnurineus $\left(T_{\mathrm{opt}} 85^{\circ} \mathrm{C}\right)$. At ambient temperatures the reduction potentials of the formate $/ \mathrm{CO}_{2}$ and $\mathrm{H}^{+} / \mathrm{H}_{2}$ couples are almost identical but at $85^{\circ} \mathrm{C}$ hydrogen production is favored and the organism is able to conserve energy for growth [48].

In fermentative metabolism, the standard EMP pathway generates $\mathrm{NADH}$ and the subsequent conversion of pyruvate to acetyl-CoA provides reduced ferredoxin in many thermophilic organisms. The low potential of the ferredoxin ( $E_{m}$ typically near $-500 \mathrm{mV}$ ) allows molecular hydrogen to be generated $\left(\mathrm{H}_{2} / 2 \mathrm{H}^{+}=-420 \mathrm{mV}\right)$ directly by ferredoxin-dependent hydrogenases. However, it is not energetically favorable for $\mathrm{NADH}\left(\mathrm{E}_{\mathrm{m}}=-320 \mathrm{mV}\right)$ to be used as an electron donor for $\mathrm{H}_{2}$ production. Thus, $\mathrm{NADH}$ oxidation must often be coupled to the production of reduced carbon products, such as lactate or ethanol from pyruvate. The necessity for an electron acceptor mandates that pyruvate, or a downstream product from pyruvate (e.g. acetaldehyde), be dedicated to this purpose. This prevents the ATP formation from pyruvate to acetate, resulting in a less energetically favorable metabolism (Figure 3).

In some microorganisms this problem is overcome by a so-called bifurcating hydrogenase, which was first discovered in the extremely thermophilic bacterium Thermotoga maritima [49]. This enzyme uses reduced ferredoxin and NADH simultaneously to produce $\mathrm{H}_{2}$. In essence, the enzyme uses the excess energy of ferredoxin oxidation to drive the endergonic oxidation of NADH. As shown in Figure 3, this has very important consequences in fermentation, as now all of the reductant generated from glucose oxidation can be used to produce $\mathrm{H}_{2}$ at the so-called Thauer limit $\left(4 \mathrm{H}_{2}\right.$ /glucose) where the maximum amount of free energy is conserved (4 ATP/glucose). It is estimated that about one-third of all ferredoxindependent hydrogenases are bifurcating enzymes [50].

The complete oxidation of glucose to $\mathrm{CO}_{2}$ theoretically yields $12 \mathrm{~mol} \mathrm{H}_{2} / \mathrm{mol}$ glucose, but fermentative pathways yield a maximum of $4 \mathrm{~mol} \mathrm{H}_{2} / \mathrm{mol}$ glucose. Due to the necessary energy 
conservation in the form of ATP, acetate rather than $\mathrm{CO}_{2}$ is generated. The Thauer limit clearly presents a barrier to biohydrogen production processes [51]. To address this limitation, an in vitro pathway was constructed by recruiting thirteen enzymes from six thermophilic organisms, focusing on oxidative and non-oxidative components of the pentose phosphate pathway (Figure 4) [52]. This achieved nearly the theoretical yield of $12 \mathrm{~mol} \mathrm{H}_{2} / \mathrm{mol}$ glucose (sucrose), or three times the Thauer limit.

\section{Alcohols}

Many ethanologenic organisms, such as Saccharomyces cerevisiae, obtain 2 ATP per glucose through traditional EMP glycolysis. The resulting pyruvate is decarboxylated via pyruvate decarboxylase complex (PDC) to acetaldehyde, which is subsequently reduced by NADH to ethanol (Figure 5). However, a thermophilic PDC, while of great potential importance, has not yet been reported. Thus most thermophilic native ethanol-producing organisms follow a threestep pathway from pyruvate to ethanol such as has been demonstrated by moderately thermophilic Clostridium thermocellum $\left(\mathrm{T}_{\mathrm{opt}} 60^{\circ} \mathrm{C}\right)$. An ethanol titer of $38 \mathrm{~g} / \mathrm{L}$ was achieved by removal of three genes that redirected carbon flux away from the organism's other native products, acetate and lactate [53].

While classical EMP provides a net ATP gain from glucose, it sacrifices the ATP-yielding hydrolysis of acetyl-CoA as it requires that pyruvate (via acetaldehyde) be utilized as an electron sink for $\mathrm{NAD}^{+}$recycling. By utilizing a unique aldehyde oxidoreductase (AOR) from $P$. furiosus, acetate can be reduced to ethanol with the reducing equivalents available from the pathway. This enzyme is capable of reducing organic acids to aldehydes, utilizing electrons from the low potential electron carrier ferredoxin. Through a NADPH-dependent alcohol dehydrogenase, these aldehydes are subsequently converted to alcohol with high efficiency. This pathway can be extended to other metabolic engineering efforts to convert organic acids to alcohols, since both the AOR and the ADH demonstrated broad substrate activity [54]. In theory, 
this pathway allows an ethanol-producing organism with EMP central glycolysis to obtain 4 ATP from glucose to ethanol, thereby doubling the energy yield of most ethanologens.

$P$. furiosus was also engineered to produce n-butanol, utilizing a template pathway from Clostridium acetobutylicum [36]. By recruiting seven enzymes from four different thermophilic species, n-butanol ( $\sim 60 \mathrm{mg} / \mathrm{L})$ production was demonstrated. Complementary to this effort, a reaction kinetic model provided insights into optimal enzyme concentrations and promoter engineering for improved n-butanol production and selectivity [55].

As mentioned previously, Caldicellulosiruptor species utilize the carbohydrate content of lignocellulosic biomass, which is metabolized to acetate, lactate and hydrogen. C. bescii was engineered to eliminate lactate formation while producing ethanol, through the insertion of an $\mathrm{NADH}-$ dependent bi-functional acetaldehyde/alcohol dehydrogenase from $C$. thermocellum for operation at $65^{\circ} \mathrm{C}$. Growth on untreated switchgrass yielded $0.6 \mathrm{~g} / \mathrm{L}$ ethanol, demonstrating direct conversion of lignocellulose to product without pre-treatment nor exogenous enzyme additions [56]. The $\mathrm{NAD}(\mathrm{P}) \mathrm{H}$-dependent acetaldehyde/alcohol dehydrogenases from Thermoanaerobacter pseudethanolicus were similarly engineered into C. bescii to more closely match enzyme thermoactivity with the optimal temperature of the host. While the operating temperature $\left(75^{\circ} \mathrm{C}\right)$ may have improved the host metabolism, the comparatively lower ethanol concentrations $(0.1 \mathrm{~g} / \mathrm{L})$ were likely a result of the limited availability of NAD(P)H [57].

Directing carbon flux away from organic acid production is critical for yield considerations in metabolic engineering efforts. Furthermore, organic acids can be toxic at low concentrations and thus even low concentrations that may be acceptable to yield may prevent the organism from reaching its potential alcohol titer. These undesired by-products, such as acetate, can significantly inhibit growth, yet complete removal of the pathways for these compounds may be infeasible for various reasons. To address these problems, detoxification by metabolite conversion to a less toxic product has been demonstrated in Thermoanaerobacterium 
saccharolyticum $\left(\mathrm{T}_{\mathrm{opt}} 60^{\circ} \mathrm{C}\right)$. By insertion of a three-enzyme heterologous pathway, the low levels of acetate were converted to acetone, thereby removing the majority of acetate inhibition. This resulted in a three-fold improvement in ethanol concentrations to $45 \mathrm{~g} / \mathrm{L}$, an industrially relevant titer [58].

\section{Conclusions}

Not only do extreme thermophiles provide a source of unconventional metabolic pathways, carbon fixation pathways, and ability to metabolize diverse substrates, there are also additional benefits related to thermodynamics at higher temperatures. As such, extremely thermophilic microorganisms can be valuable resources for addressing the current metabolic engineering barriers. By deliberate and structured design of pathways inspired by these non-model organisms, there now exist new opportunities for commercially relevant processes. Many of these metabolic features have been validated as a 'proof-of-concept', so it remains to be seen whether and how extreme thermophiles will fit into the emerging industrial biotechnology sector.

\section{Acknowledgments}

This work was supported by grants to RMK and MWWA by the US Department of Energy Research ARPA-E Electrofuels Program (DE-AR0000081), the US National Science Foundation (CBET-1264052, CBET-1264053), the US Air Force Office of Scientific Research (AFOSR) (FA9550-13-1-0236), and the BioEnergy Science Center (BESC), a U.S. Department of Energy Bioenergy Research Center supported by the Office of Biological and Environmental Research in the DOE Office of Science. 


\section{References and Recommended Reading}

Papers of particular interest published within the period or review have been highlighted as follows:

- of special interest

•- of outstanding interest

1. Hutchison CA, Chuang RY, Noskov VN, Assad-Garcia N, Deerinck TJ, Ellisman MH, Gill J, Kannan K, Karas BJ, Ma L, et al.: Design and synthesis of a minimal bacterial genome. Science 2016, 351:1414-U1473.

2. Loder AJ, B.M. Zeldes, J.M. Conway, J.A. Counts, C.T. Straub, P.A. Khatibi, L.L. Lee, N.P. Vitko, M.W. Keller, A.M. Rhaesa, G.M. Rubenstein, I.M. Scott, G.L. Lipscomb, M.W.W. Adams, and R.M. Kelly: Extreme Thermophiles as Metabolic Engineering Platforms: Strategies and Current Perspective. In Industrial Biotechnology. Edited by C Wittmann JL: Wiley-VCH Biotechnology Series; 2016. [S.-Y. Lee JN, G. Stephanopoulos (Series Editor): Wiley-VCH Biotechnology Series

3. Zeldes BM, Keller MW, Loder AJ, Straub CT, Adams MW, Kelly RM: Extremely thermophilic microorganisms as metabolic engineering platforms for production of fuels and industrial chemicals. Front Microbiol 2015, 6:1209.

4. Aucelli T, Contursi P, Girfoglio M, Rossi M, Cannio R: A spreadable, non-integrative and high copy number shuttle vector for Sulfolobus solfataricus based on the genetic element pSSVx from Sulfolobus islandicus. Nucleic Acids Res 2006, 34:e114.

5. Wagner M, van Wolferen M, Wagner A, Lassak K, Meyer BH, Reimann J, Albers SV:

Versatile genetic tool box for the crenarchaeote Sulfolobus acidocaldarius. Front Microbiol 2012, 3. 
6. Worthington P, Hoang V, Perez-Pomares F, Blum P: Targeted disruption of the alphaamylase gene in the hyperthermophilic archaeon Sulfolobus solfataficus. $J$ Bacteriol 2003, 185:482-488.

7. Takemasa R, Yokooji $Y$, Yamatsu A, Atomi H, Imanaka $\mathrm{T}$ : Thermococcus kodakarensis as a host for gene expression and protein secretion. Appl Environ Microbiol 2011, 77:2392-2398.

8. Farkas J, Stirrett K, Lipscomb GL, Nixon W, Scott RA, Adams MW, Westpheling J: Recombinogenic properties of Pyrococcus furiosus strain COM1 enable rapid selection of targeted mutants. Appl Environ Microbiol 2012, 78:4669-4676.

9. Waege I, Schmid G, Thumann S, Thomm M, Hausner W: Shuttle vector-based transformation system for Pyrococcus furiosus. Appl Environ Microbiol 2010, 76:3308-3313.

10. Hashimoto $\mathrm{Y}$, Yano T, Kuramitsu S, Kagamiyama H: Disruption of Thermus thermophilus genes by homologous recombination using a thermostable kanamycin-resistant marker. FEBS Lett 2001, 506:231-234.

11. Yao S, Mikkelsen MJ: Metabolic engineering to improve ethanol production in Thermoanaerobacter mathranii. Appl Microbiol Biotechnol 2010, 88:199-208.

12. Chung D, Farkas J, Huddleston JR, Olivar E, Westpheling J: Methylation by a unique alpha-class N4-cytosine methyltransferase is required for DNA transformation of Caldicellulosiruptor bescii DSM6725. PLoS One 2012, 7:e43844.

13. Lipscomb GL, Schut GJ, Thorgersen MP, Nixon WJ, Kelly RM, Adams MWW: Engineering hydrogen gas production from formate in a hyperthermophile by heterologous production of an 18-subunit membrane-bound complex. J Biol Chem 2014, 289:2873-2879.

- Hyperthermophile engineered to obtain energy from oxidation of carbon monoxide through insertion of 16 gene cluster. 
14. Hoseki J, Yano T, Koyama Y, Kuramitsu S, Kagamiyama H: Directed evolution of thermostable kanamycin-resistance gene: a convenient selection marker for Thermus thermophilus. J Biochem 1999, 126:951-956.

15. Lipscomb GL, Conway JM, Blumer-Schuette SE, Kelly RM, Adams MWW: A highly thermostable kanamycin resistance marker expands the tool kit for genetic manipulation of Caldicellulosiruptor bescii. Appl Environ Microbiol 2016, 82:44214428.

- Versatile and simplified genetic system developed allowing antibiotic (kanamycin) resistance selection.

16. Maezato $\mathrm{Y}$, Johnson T, McCarthy S, Dana K, Blum P: Metal resistance and lithoautotrophy in the extreme thermoacidophile Metallosphaera sedula. J Bacteriol 2012, 194:6856-6863.

17. Han DM, Norris SM, Xu ZH: Construction and transformation of a Thermotoga-E. coli shuttle vector. BMC Biotechnol 2012, 12.

18. Han DM, Xu H, Puranik R, Xu ZH: Natural transformation of Thermotoga sp strain RQ7. BMC Biotechnol 2014, 14.

19. Basen M, Sun J, Adams MW: Engineering a hyperthermophilic archaeon for temperature-dependent product formation. mBio 2012, 3:e00053-00012.

20. Keller MW, Schut GJ, Lipscomb GL, Menon AL, Iwuchukwu IJ, Leuko TT, Thorgersen MP, Nixon WJ, Hawkins AS, Kelly RM, et al.: Exploiting microbial hyperthermophilicity to produce an industrial chemical, using hydrogen and carbon dioxide. Proc NatI Acad Sci U S A 2013, 110:5840-5845.

21. Nguyen DM, Lipscomb GL, Schut GJ, Vaccaro BJ, Basen M, Kelly RM, Adams MW:

Temperature-dependent acetoin production by Pyrococcus furiosus is catalyzed by a biosynthetic acetolactate synthase and its deletion improves ethanol production. Metab Eng 2016, 34:71-79. 
22. Grogan DW: Phenotypic characterization of the archaebacterial genus Sulfolobus: comparison of five wild-type strains. J Bacteriol 1989, 171:6710-6719.

23. Ulas T, Riemer SA, Zaparty M, Siebers B, Schomburg D: Genome-scale reconstruction and analysis of the metabolic network in the hyperthermophilic archaeon Sulfolobus solfataricus. PLoS One 2012, 7:e43401.

- Analysis of metabolic pathways at genome scale demonstrates toolbox for future metabolic engineering efforts.

24. Wolf J, Stark H, Fafenrot K, Albersmeier A, Pham TK, Muller KB, Meyer BH, Hoffmann L, Shen L, Albaum SP, et al.: A systems biology approach reveals major metabolic changes in the thermoacidophilic archaeon Sulfolobus solfataricus in response to the carbon source L-fucose versus D-glucose. Mol Microbiol 2016.

25. Soderberg T: Biosynthesis of ribose-5-phosphate and erythrose-4-phosphate in archaea: a phylogenetic analysis of archaeal genomes. Archaea 2005, 1:347-352.

26. Blumer-Schuette SE, Brown SD, Sander KB, Bayer EA, Kataeva I, Zurawski JV, Conway JM, Adams MW, Kelly RM: Thermophilic lignocellulose deconstruction. FEMS Microbiol Rev 2014, 38:393-448.

27. Zurawski JV, Conway JM, Lee LL, Simpson HJ, Izquierdo JA, Blumer-Schuette S, Nookaew I, Adams MWW, Kelly RM: Comparative Analysis of extremely thermophilic Caldicellulosiruptor species reveals common and unique cellular strategies for plant biomass utilization. Appl Environ Microbiol 2015, 81:7159-7170.

28. Conway JM, Pierce WS, Le JH, Harper GW, Wright JH, Tucker AL, Zurawski JV, Lee LL, Blumer-Schuette SE, Kelly RM: Multidomain, surface layer-associated glycoside hydrolases contribute to plant polysaccharide degradation by Caldicellulosiruptor species. J Biol Chem 2016, 291:6732-6747.

29. Brunecky R, Alahuhta M, Xu Q, Donohoe BS, Crowley MF, Kataeva IA, Yang SJ, Resch MG, Adams MW, Lunin VV, et al.: Revealing nature's cellulase diversity: the 
digestion mechanism of Caldicellulosiruptor bescii CelA. Science 2013, 342:15131516.

- Characterization of most highly cellulolytic enzyme from the extreme thermophile, Caldicellulosiruptor bescii.

30. Ji SQ, Wang B, Lu M, Li FL: Direct bioconversion of brown algae into ethanol by thermophilic bacterium Defluviitalea phaphyphila. Biotechnol Biofuels 2016, 9.

- Conversion of algae to ethanol by thermophilic bacterium. Shows potential for aqueous/marine based photosynthetic organisms as renewable feedstocks for biofuels.

31. Ji SQ, Wang B, Lu M, Li FL: Defluviitalea phaphyphila sp. nov., a novel thermophilic bacterium that degrades brown algae. Appl Environ Microbiol 2016, 82:868-877.

32. Berg IA, Kockelkorn D, Buckel W, Fuchs G: A 3-hydroxypropionate/4-hydroxybutyrate autotrophic carbon dioxide assimilation pathway in Archaea. Science 2007, 318:1782-1786.

33. Huber H, Gallenberger M, Jahn U, Eylert E, Berg IA, Kockelkorn D, Eisenreich W, Fuchs G: A dicarboxylate/4-hydroxybutyrate autotrophic carbon assimilation cycle in the hyperthermophilic archaeum Ignicoccus hospitalis. Proc Natl Acad Sci U S A 2008, 105:7851-7856.

34. Loder AJ, Y. Han, A.B. Hawkins, H. Lian, G.L. Lipscomb, G.J. Schut, M.W. Keller, M.W.W. Adams, and R.M. Kelly: Reaction kinetic analysis of the 3-hydroxypropionate/4hydroxybutyrate $\mathrm{CO} 2$ fixation cycle in the extremely thermoacidophilic archaea. Metabolic Eng 2016, epub.

35. Hawkins AB, Lian H, Zeldes BM, Loder AJ, Lipscomb GL, Schut GJ, Keller MW, Adams MW, Kelly RM: Bioprocessing analysis of Pyrococcus furiosus strains engineered for CO(2)-based 3-hydroxypropionate production. Biotechnol Bioeng 2015, 112:1533-1543. 
36. Keller MW, Lipscomb GL, Loder AJ, Schut GJ, Kelly RM, Adams MW: A hybrid synthetic pathway for butanol production by a hyperthermophilic microbe. Metab Eng 2015, 27:101-106.

37. Holmes DE, Risso C, Smith JA, Lovley DR: Anaerobic oxidation of benzene by the hyperthermophilic archaeon Ferroglobus placidus. Appl Environ Microbiol 2011, 77:5926-5933.

38. Schmid G, Rene SB, Boll M: Enzymes of the benzoyl-coenzyme A degradation pathway in the hyperthermophilic archaeon Ferroglobus placidus. Environmental Microbiology 2015, 17:3289-3300.

39. Huber G, Spinnler C, Gambacorta A, Stetter KO: Metallosphaera sedula gen. nov. and sp. nov. represents a new genus of aerobic, metal-mobilizing, thermoacidophilic archaebacteria. Syst Appl Microbiol 1989, 12:38-47.

40. Huber G, Stetter KO: Sulfolobus metallicus, sp. nov., a novel strictly chemolithoautotrophic thermophilic archaeal species of metal-mobilizers. Syst Appl Microbiol 1991, 14:372-378.

41. Kletzin A, Urich T, Muller F, Bandeiras TM, Gomes CM: Dissimilatory oxidation and reduction of elemental sulfur in thermophilic archaea. J Bioenerg Biomembr 2004, 36:77-91.

42. Urich T, Gomes CM, Kletzin A, Frazao C: X-ray Structure of a self-compartmentalizing sulfur cycle metalloenzyme. Science 2006, 311:996-1000.

43. Kletzin A: Coupled enzymatic production of sulfite, thiosulfate, and hydrogen sulfide from sulfur: purification and properties of a sulfur oxygenase reductase from the facultatively anaerobic archaebacterium Desulfurolobus ambivalens. J Bacteriol 1989, 171:1638-1643.

44. Janosch C, Remonsellez F, Sand W, Vera M: Sulfur Oxygenase Reductase (SOR) in the moderately thermoacidophilic leaching bacteria: studies in Sulfobacillus 
thermosulfidooxidans and Acidithiobacillus caldus. Microorganisms 2015, 3:707724.

45. Schut GJ, Lipscomb GL, Nguyen DM, Kelly RM, Adams MW: Heterologous production of an energy-conserving carbon monoxide dehydrogenase complex in the hyperthermophile Pyrococcus furiosus. Front Microbiol 2016, 7:29.

46. Wan Tea: A biological process effective for the conversion of CO-containing industrial waste gas to acetate. Bioresource Technology 2016, 211:792-796.

47. Verhaart MR, Bielen AA, van der Oost J, Stams AJ, Kengen SW: Hydrogen production by hyperthermophilic and extremely thermophilic bacteria and archaea: mechanisms for reductant disposal. Environ Technol 2010, 31:993-1003.

48. Kim YJ, Lee HS, Kim ES, Bae SS, Lim JK, Matsumi R, Lebedinsky AV, Sokolova TG, Kozhevnikova DA, Cha SS, et al.: Formate-driven growth coupled with $\mathbf{H ( 2 )}$ production. Nature 2010, 467:352-355.

49. Schut GJ, Adams MW: The iron-hydrogenase of Thermotoga maritima utilizes ferredoxin and NADH synergistically: a new perspective on anaerobic hydrogen production. J Bacteriol 2009, 191:4451-4457.

50. Peters JW, Miller AF, Jones AK, King PW, Adams MW: Electron bifurcation. Curr Opin Chem Biol 2016, 31:146-152.

51. Thauer RK, Jungermann K, Decker K: Energy conservation in chemotrophic anaerobic bacteria. Bacteriol Rev 1977, 41:100-180.

52. Zhu ZG, Tam TK, Sun FF, You C, Zhang YHP: A high-energy-density sugar biobattery based on a synthetic enzymatic pathway. Nature Communications 2014, 5.

-. Demonstrates in vitro route for high sugar-to-energy bioconversion process.

53. Argyros DA, Tripathi SA, Barrett TF, Rogers SR, Feinberg LF, Olson DG, Foden JM, Miller BB, Lynd LR, Hogsett DA, et al.: High ethanol titers from cellulose by using 
metabolically engineered thermophilic, anaerobic microbes. Appl Environ Microbiol 2011, 77:8288-8294.

54. Basen M, Schut GJ, Nguyen DM, Lipscomb GL, Benn RA, Prybol CJ, Vaccaro BJ, Poole FL, 2nd, Kelly RM, Adams MW: Single gene insertion drives bioalcohol production by a thermophilic archaeon. Proc Natl Acad Sci U S A 2014, 111:17618-17623.

- Broad substrate specificity aldehyde oxidoreductase allows direct conversion from organic acid to aldehyde. Permits energy positive pathway from pyruvate to ethanol.

55. Loder AJ, Zeldes BM, Garrison GD, 2nd, Lipscomb GL, Adams MW, Kelly RM: Alcohol selectivity in a synthetic thermophilic $n$-butanol pathway is driven by biocatalytic and thermostability characteristics of constituent enzymes. Appl Environ Microbiol 2015, 81:7187-7200.

56. Chung D, Cha M, Guss AM, Westpheling J: Direct conversion of plant biomass to ethanol by engineered Caldicellulosiruptor bescii. Proc Natl Acad Sci U S A 2014, 111:8931-8936.

57. Chung D, Cha M, Snyder EN, Elkins JG, Guss AM, Westpheling J: Cellulosic ethanol production via consolidated bioprocessing at 75 degrees $\mathrm{C}$ by engineered Caldicellulosiruptor bescii. Biotechnol Biofuels 2015, 8:163.

58. Shaw AJ, Miller BB, Rogers SR, Kenealy WR, Meola A, Bhandiwad A, Sillers WR, Shikhare I, Hogsett DA, Herring CD: Anaerobic detoxification of acetic acid in a thermophilic ethanologen. Biotechnol Biofuels 2015, 8:75. 


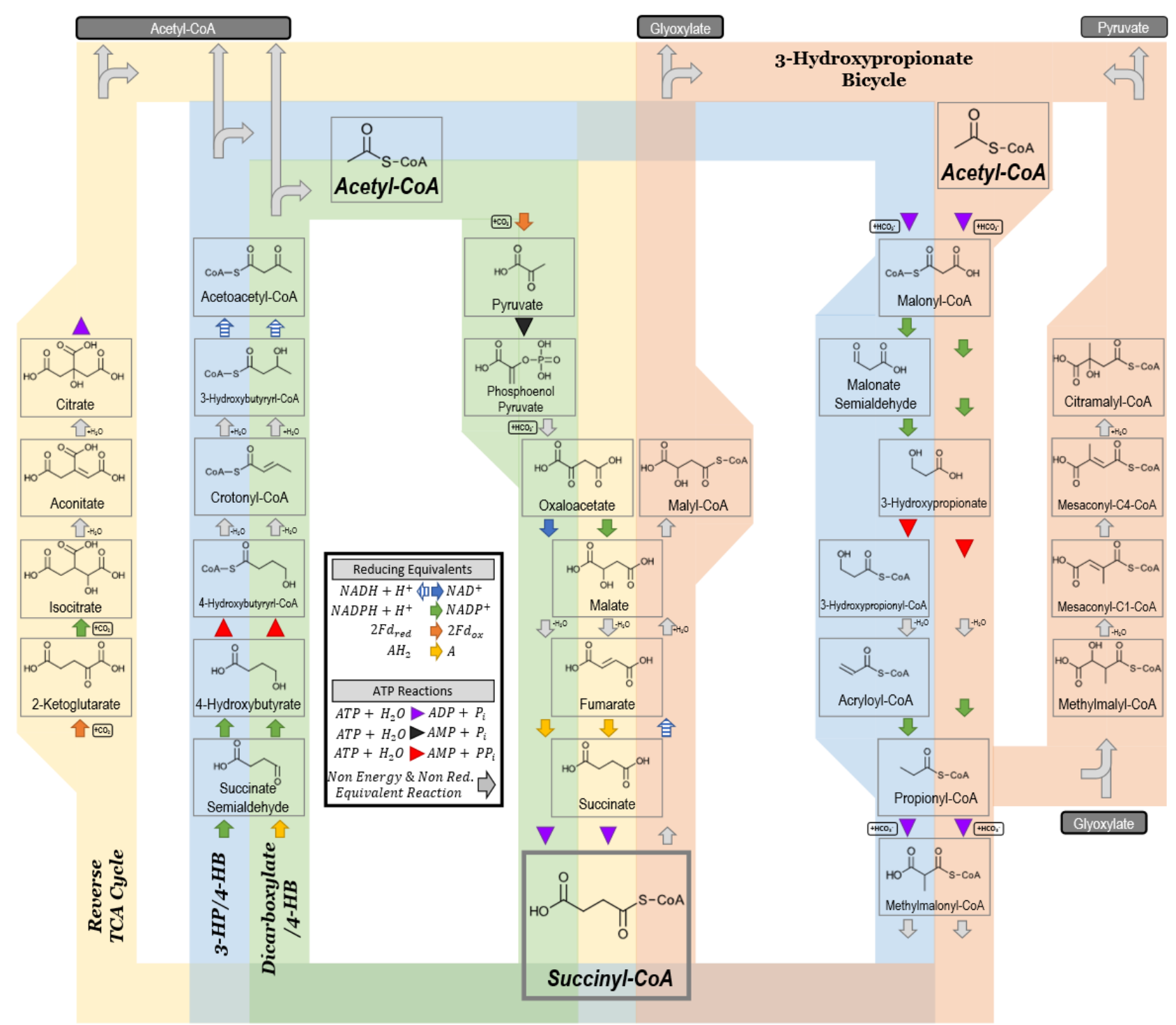

Figure 1. Four carbon fixation cycles found in thermophilic organisms: Reverse TCA Cycle (yellow), 3-Hydroxypropionate/4-Hydroxbutyrate (blue), dicarboxylate/4-hydroxybutyrate (green), and 3-hydroxypropionate bicycle (orange).

${ }^{*} \mathrm{AH}_{2}$ indicates any or unknown electron carrier. A represents its oxidized counterpart.

${ }^{* *} \mathrm{CoA}$ inclusion and dissociation reactions not explicitly shown. 

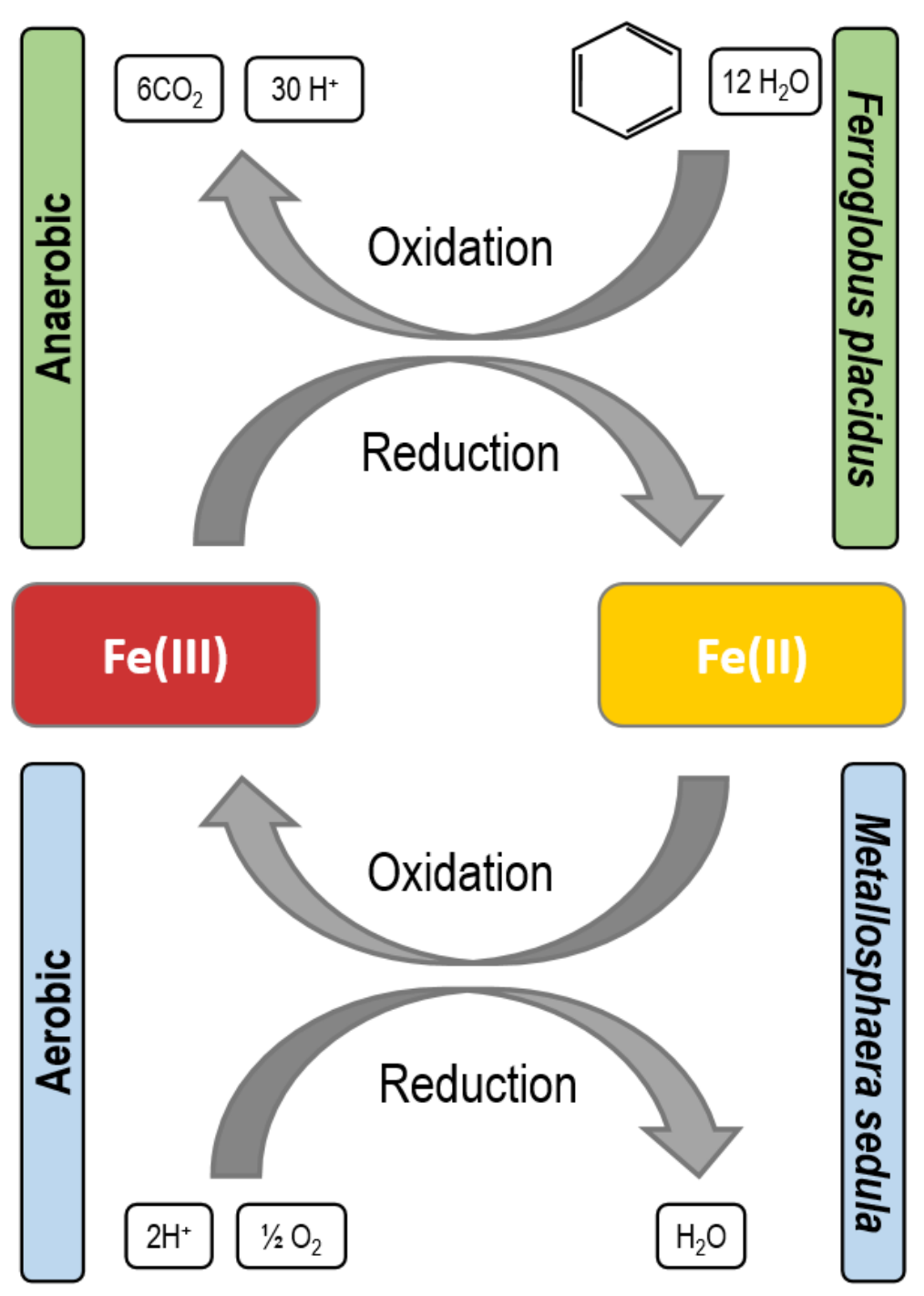

Figure 2. Iron as an electron donor and acceptor by acidothermophiles. Aerobic oxidation of $\mathrm{Fe}^{2+}$ by $\mathrm{M}$. sedula allows the fixation of carbon dioxide. Anaerobic reduction of $\mathrm{Fe}^{3+}$ by F. placidus permits oxidation of reduced carbon in benzene (39). 


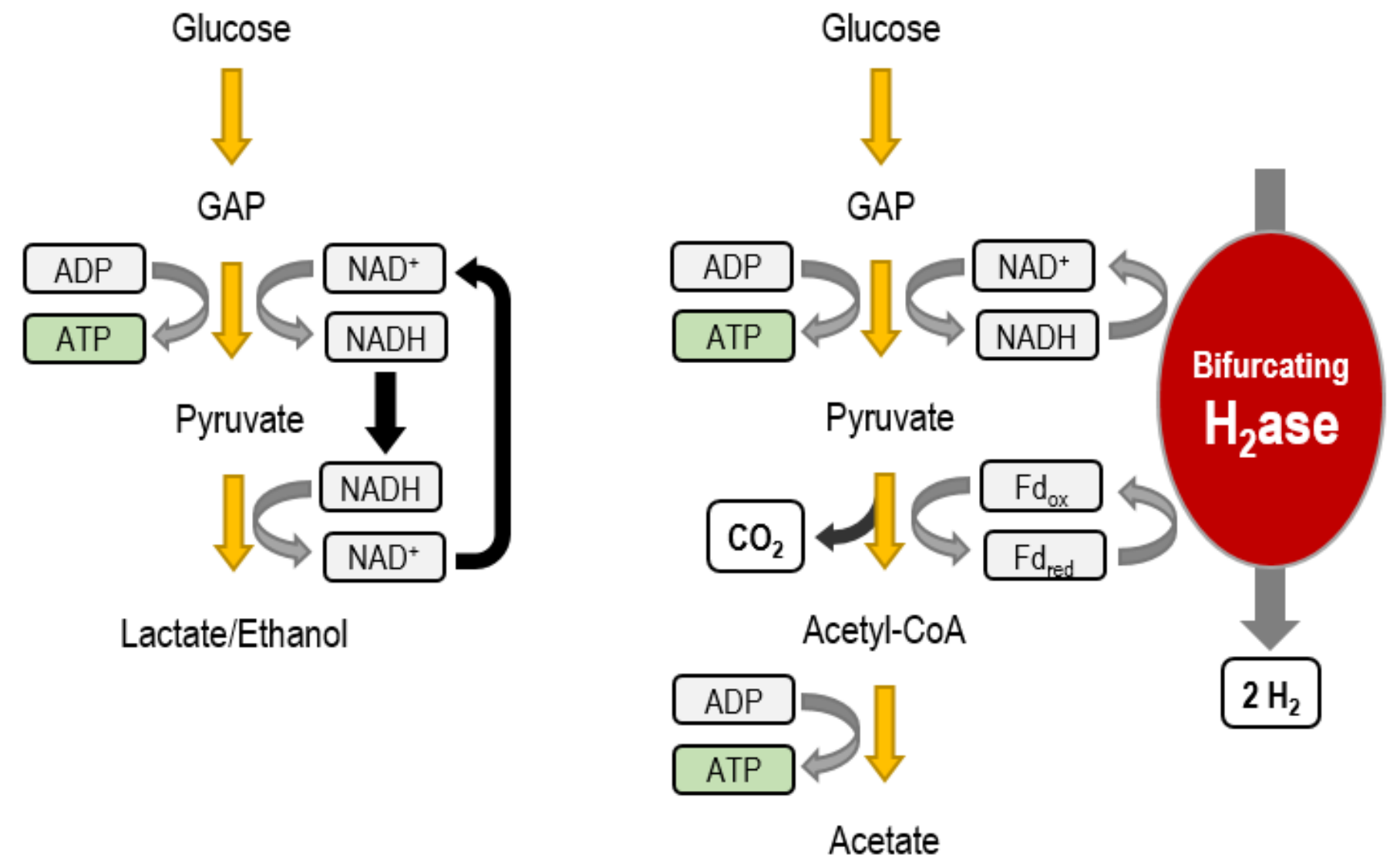

Figure 3. (Left) Electrons from reduced electron carriers require high potential electron acceptor in the form of pyruvate or an aldehyde, resulting in energy yield of 2 ATP per glucose. (Right) Bifurcating hydrogenase allows energy yield of 4 ATP per glucose by generation of hydrogen from reduced electron carriers. (49) 


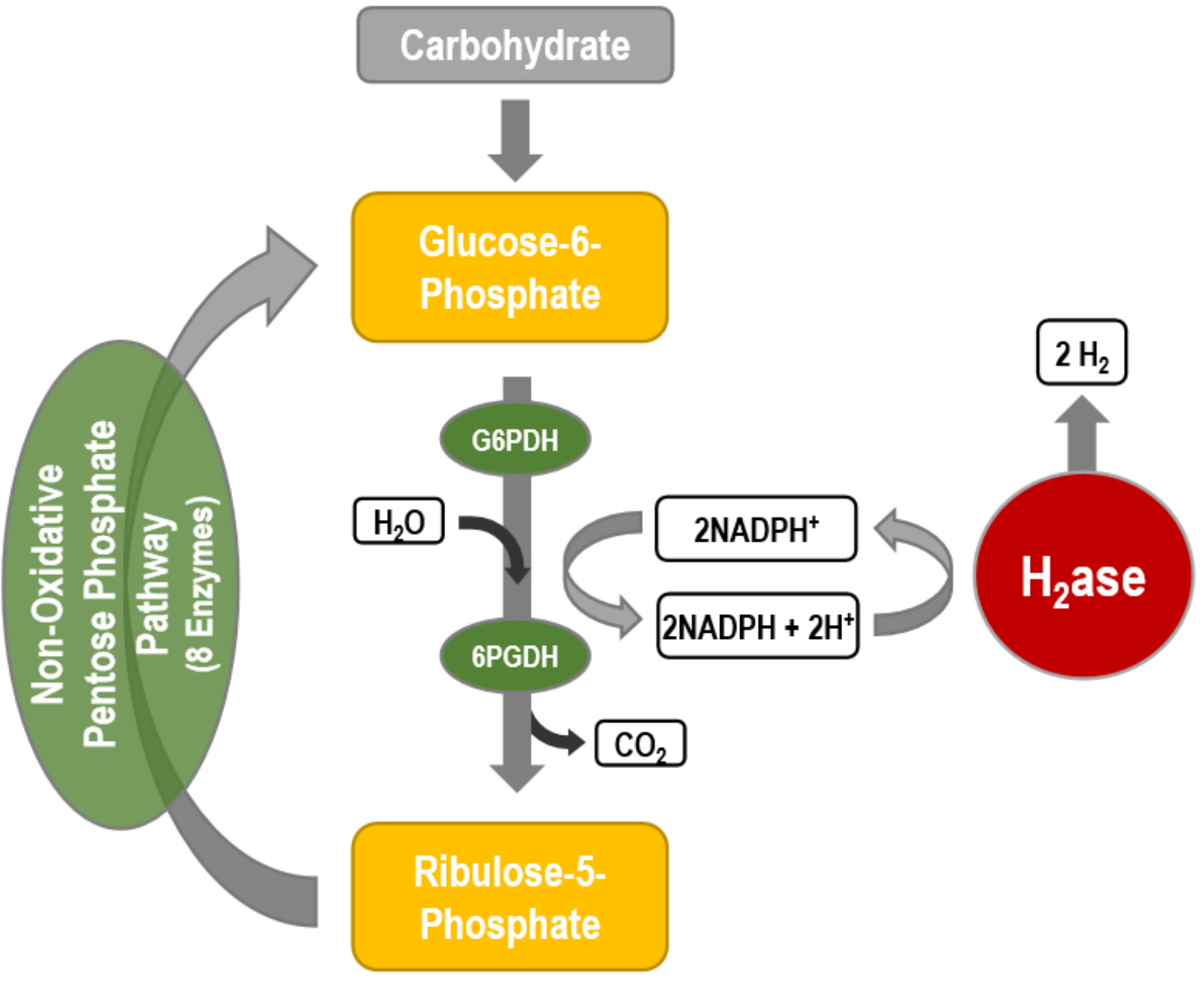

Figure 4. In vitro route from carbohydrates to hydrogen at near theoretical yield (24 mol $\mathrm{H}_{2}$ per dihexose) utilizing eleven thermophilic enzymes recruited from four different species (52)

*Two mesophilic and two thermophilic enzymes, all from different species, were utilized for conversion of sucrose to glucose-6-phosphate (not shown). 


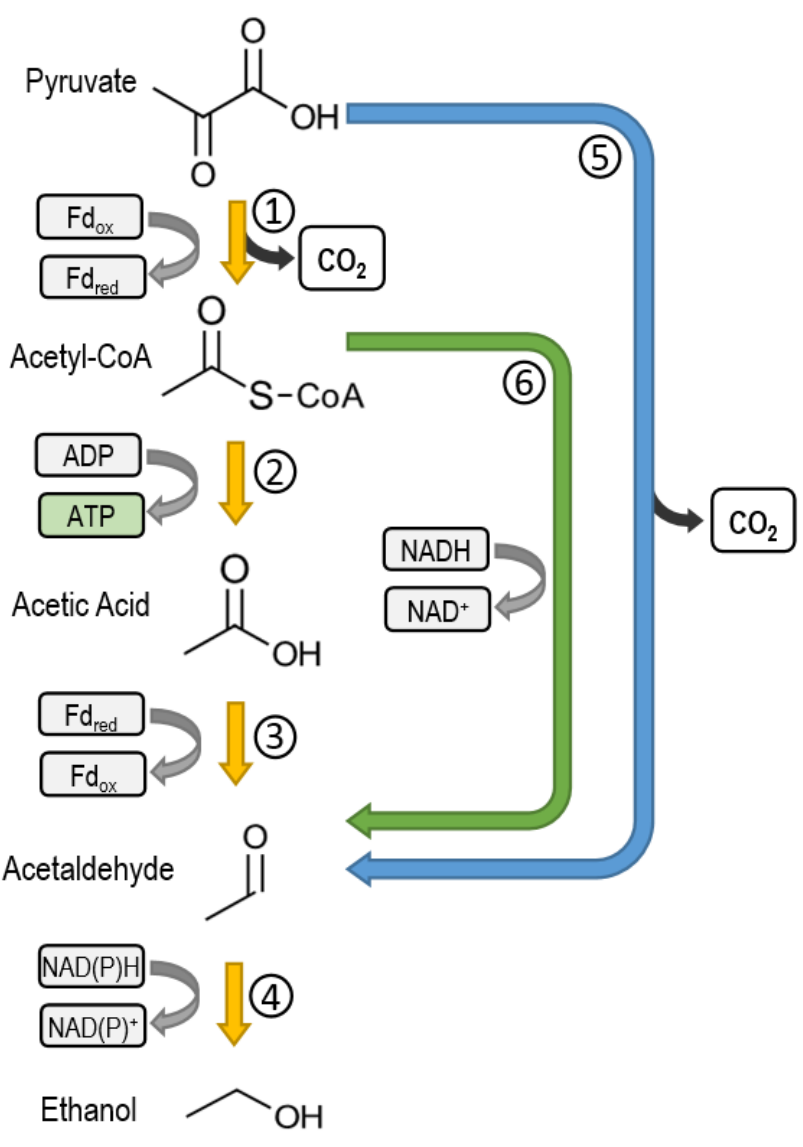

Figure 5. Three routes from pyruvate to ethanol: four enzyme, ATP-generating pathway utilizing single step reduction of acetate to acetaldehyde (1-4 yellow), two enzyme pathway utilizing direct decarboxylation of pyruvate to acetaldehyde ( $5 \& 4$ - blue), and three enzyme pathway with reduced ferredoxin generated during pyruvate to acetyl-CoA step followed by consumption of NADH during conversion to acetaldehyde. (1, 6 , \& 4 - green)

Acetyl-CoA Synthetase (ACS)[1], Acetyl-CoA Dehydrogenase (ACD), Aldehyde Oxidoreductase (AOR)[3], Alcohol Dehydrogenase (AdhA) [4], Pyruvate Decarboxylase Complex (PDC) [5], and Acetaldehyde Dehydrogenase (ALDH) [6]. 


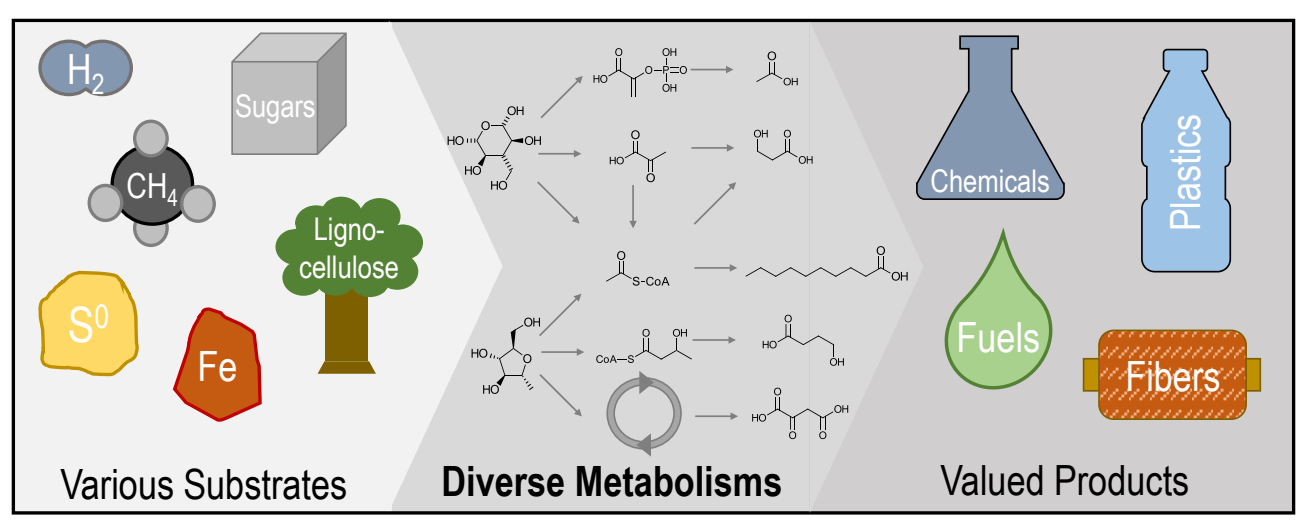

